\title{
A Hindu Worldview of Adult Learning in the Workplace
}

\author{
H. S. Ashok \\ M. S. Thimmappa
}

The problem and the solution. The Hindu religion has abundant literature applicable to human resource development (HRD). Using a holistic approach, Hindu texts address the process of developing people at both the micro and macro levels. Theoretical constructs related to adult learning in the workplace and organization development from the ancient Hindu scriptures are examined.

Keywords: adult learning; Hinduism; Asian HRD; organization development

Hindu religion, one of the ancient religions of the world, has abundant literature concerning adult learning and human resource development. It envisages a holistic approach in understanding and enhancing human resources. Hindu texts, the Vedas, Upanishads (detailed commentary and interpretation of Vedas which embodies Hindu philosophy), Puranas, and others, deliberate on the process of the development of mankind through different stages toward self-realization. They offer several alternative paradigms that can be applied to understand the individual at the micro level, as well as the universe at the macro level.

Hinduism takes a holistic approach in understanding behavior. Individuals, organizations, society, the universe, and the cosmos are all interrelated and integrated. The development of human resources is thus viewed in terms of facilitating the individual to realize oneself and to understand the intricate relationship between the individual and his or her role in the organization, the role of the organization the society, society in the universe, and the universe within the cosmos. Although some Upanishads (the end part of Vedas, the embodiment of all scriptures of ancient Indian wisdom) and Yoga sutras (principles delineated by the sage Pathanjali to be practiced by all for achieving the goals of life) deliberate on understanding human resources from an individual perspective, Manu smriti (principles of conduct and social organization written by Manu), Bhagavad-Gita (the song of God found in the epic Mahabharatha that 
embodies dynamics of human behavior across stages of development), and other ancient Hindu scriptures, deal with practices and procedures to understand human behavior at a macro level.

According to Hindu philosophy, every individual is perceived as having a unique potential. Each individual self (atman) is wrapped up within five sheaths, called panchakoshas or koshas (Radhakrishnan, 1953). During the process of development, the individual is expected to overcome these five sheaths and ultimately reach a stage wherein the self unifies with the universal self (brahman). The five koshas (Radhakrishnan, 1953) are annamaya (body), pranamaya (breath), manomaya (mind), vigyänamaya (intellect), and änandamaya (bliss). Individual differences in abilities, performance, and others can be attributed to the different levels from which individuals operate.

\section{The Koshas}

HRD may be conceived through the Upanishads as providing facilitating factors for the personal self to attain unison with the universal self (Brahman). Brief operational definitions of these koshas and how they affect individual behavior follow.

Annamaya kosha (bodily sheath): This kosha determines the structure, strength, and overall health of the gross (physical) body. The nutritional quality of what one eats affects the development of the gross body, but the subtle properties and purity of food intake influence inner characteristics and, thus, the evolution of this kosha.

Pranamaya kosha (vital/breath sheath): The reservoir of vital energy-the source of liveliness, activity, and inner strength-comes from this kosha. Disorder, malice, or deficiencies in this kosha give rise to psychosomatic diseases, mental weakness, and mental complexities. This kosha is maintained in order by harmonizing the level of präna (vital force).

Manomaya kosha (mental sheath): This kosha governs intelligence, intrinsic tendencies, and continuous activities of the mind at both conscious and unconscious levels.

Vigyänamaya kosha (intellectual sheath): This kosha is the source of ultimate knowledge and self-realization of the soul. The true existence of the self is experienced as different from the body, vital energy, and mind in the refined state of this kosha. On success of the associated sädhanäs (practices), the soul realizes its divine origin.

Änandamaya kosha (bliss sheath): This kosha contains the source of divine bliss - a state of mind experienced after unification of the soul with its eternal origin that leads to ultimate spiritual realization, sublime transformation, and 
divine expansion of the self as unified with the omnipresent impulses of the supreme consciousness.

These koshas can be construed in a hierarchical manner, and at any given point in time, the individual self may operate from any one of these koshas. Thus, the potential driving force for an individual originates from a given kosha. Understanding the level from which an individual is operating enables the development of human resources in the work place. Effective HRD thus should facilitate individuals ascending from a lower level to a higher level, uncovering the sheaths in sequence and enabling the individual to operate at the änandamaya kosha, at which the individual would be able to integrate the personal self, and his or her role in the organization, with that of the universal atman (Brahman). Until the individual is able to unfold the sheaths, utilization of one's potential is hard to achieve. When an individual is functioning from the lower koshas, his or her behavior is influenced by feelings and emotions ( raga), biases and prejudices, and restricted perceptions of reality (avidya).

Many behavioral problems at work, such as lack of motivation, interpersonal conflicts, competition and rivalry, greed for power, and discrepancy between one's potential and performance could be understood from this perspective. Effective HRD facilitates an individual's understanding and progress in unfolding these sheaths, resulting in personal growth and development that fosters more effective organizations. Learning plays a significant role in unfolding these sheaths. Input that one receives through learning is found to be contingent upon the stages of development. Hinduism recognizes four stages of growth and development across the life span (ashramas). Specific goals (purusharthas) have been identified corresponding to the four stages of development.

\section{Ashramas and Purusharthas}

At a micro level, Hinduism deals with growth and development across several developmental stages called ashramas (Hiriyanna, 2002), including the following: (a) balya (childhood), (b) koumarya (youth), (c) gruhastha (adult), (d) vanaprastha (recluse), and (e) sanyasa (ascetic). Appropriate goals (purusharthas) for each stage are as follows: (a) dharma (duty), (b) artha (wealth), (c) kama (desire), and (d) moksha (liberation). The ultimate goal of self-realization (atma sakshatkara), or unification with the Brahman, is possible by following a way of life that unfolds the koshas through these stages of life and the related goals. The specific goals appropriate to these stages of development could be realized and achieved by following a proper way of life demonstrated by the practice of yoga.

\section{Yoga}

Following a proper way of life is delineated in ashtanga yoga (Hiriyanna, 2002). Pathanjali, in his yoga sutra (Srivastava, 2001), advocated that yoga should be a way of life and not practiced as a set of exercises. Practice of yoga 
provides stability, skillfulness, and self-realization (samatva, koushala, atma sakshatkara). Ashtanga yoga delineates eight steps through which one can ascend from the annamaya kosha (bodily sheath) to the anandamaya kosha (bliss sheath).

\section{Ashtanga (eight-limbed) Yoga}

The first two limbs of ashtanga yoga are termed yamas (restraints) and niyamas (observances). They are commonsense guidelines for leading a healthier, happier life and for bringing spiritual awareness into a social context. They help in the development of compassion and awareness of ourselves and others. They help in developing a deeper respect for the things we value, such as pleasure, economic achievement, duty, and obligation to others. They foster liberation from all biologically and socially oriented limitations, and assist in finding a meaningful life by unveiling the sheaths across the stages of development.

Yamas and niyamas are not about right and wrong. They are about being honest with the true self. Living according to these principles is about living our lives in a better way, making it possible to connect with the Divine.

The third limb of ashtanga yoga is the Asanas (bodily postures). Besides various physiological benefits, they positively affect the mind, life force energies, and creative intelligence. They make the mind strong, thus enabling the human body to suffer pain and unhappiness stoically and with fortitude by enhancing tolerance to sufferings and unhappiness.

The fourth limb of ashtanga yoga, the Pranayama (breathing mechanisms), is about controlling the life force or prana. The practices of pranayama develop correct breathing techniques and help manipulate energies. Most of us breathe incorrectly, using only half of our lung capacity. Pranayama is a technique that reeducates one's breathing process, helps release tensions, and develops a relaxed state of mind. It also balances our nervous system and encourages creative thinking. In addition, by increasing the amount of oxygen to our brain, it improves mental clarity, alertness, and physical well-being.

Pratyahara (withdrawal of senses), the fifth limb, involves managing the senses and going beyond them instead of simply closing and suppressing them.

The sixth limb, dharana (focusing), involves developing and extending our powers of concentration. This consists of various ways of directing and controlling our attention and mind-fixing skills, such as concentrating on the chakras (energy centers) or turning inward.

In dhyana (meditation), the seventh limb, a delicate state of awareness is developed. This leads to samadhi, or total absorption, the final limb. It is the ability to become one with the true self and to merge into the object of concentration. In this state of mind, the perceiver and the object of perception unite through the very act of perception - a true unity of all thought and action, the ultimate yoga or connection between the individual and the universal soul. 


\section{Application of Hindu Principles to the Workplace}

Human resource management and development are a joint responsibility of the individual and the organization. While the practice of ashtanga yoga facilitates knowing inner potential and realizing oneself at an individual level, practice of karma yoga (yoga of action) at the organizational level facilitates the realization the self through work. The principle of nishkama karma (desireless action) guarantees total commitment to and involvement in the work and self-realization through work.

The holistic and integrated approach of Hinduism provides an alternative paradigm to understand workplace human relations issues. Application of this alternate paradigm would help in optimizing human resource processes and sustaining them.

\section{Adult Learning in the Workplace}

Hinduism views learning as a continuous process. Across the different stages of development (ashramas), learning occurs. Formal learning takes place at educational institutions, or in the facilitating environment provided by the Guru (teacher) during bramhacharya (stage of studenthood). Formal learning results in acquired knowledge and skills that need to be put to practice for the benefit of the individual, and of the society at large. Gratification of the goals of life (purusharthas) at the later stages of development depends upon learning at the later stages.

Adult learning, especially in the workplace, is contingent upon reorienting oneself. Unlike the other religions, Hinduism advocates the use of subjective and experiential methods in contrast to empirical methods (Srivastava, 2001). The methods of antaravalokana (introspection), svadhyaya (self-study based on personal experience) help the individual ascend from egocentric orientation to sociocentric and cosmo centric orientations (Chakraborty, 2005). Alternatively, organizations could provide a more facilitating environment to its employees through its policies and programs such as (a) providing a learning environment that fosters the fulfillment of the inherent desire of achieving oneness or ekatmanubhuti (unison of self with the ultimate self-Brahman); (b) incorporating learning programs based on the practice of both karma sadhana (achieving the practices of actions) and dharma sadhana (in righteous manner); (c) providing the necessary learning experiences that help to reduce the egocentric, self-centered nature of the individual; and (d) practicing more sociocentric activities that help in attainment of cosmo-centricity/oneness (ekanubhuti). Regular practice of karma yoga, indulging in svadhyaya (experiential learning), and adopting antharavalokana (introspection) help members of the organization to learn and adopt the appropriate methods that not only help them in satisfying individual needs but also organizational goals (Srivastava, 2001). 


\section{Implications for Practice}

\section{The Problem of Work Stress}

The modern age is an era of stress. Work, our professions, and organizations are potential sources of stress that have detrimental effects on both individuals and organizations. Susceptibility to various psychosomatic disorders, allergies, and psychological and physical morbidity is the toll stress may have on individuals. Organizational ramifications of stress are multifarious, ranging from lowered productivity, absenteeism and accidents to lack of employee morale and motivation and declines in personal and organizational values and ethics (Hellriegel, Slocum, \& Woodman, 1995).

Regular practice of ashtanga yoga would enable individuals to handle the negative consequences of stress such as the psycho-physiological dysfunctions. Through the practice of yoga, we become aware of the interconnectedness between our emotional, mental, and physical levels. Gradually this awareness leads to an understanding of the more subtle areas of existence. The ultimate goal of yoga is to make it possible to fuse together the gross material (annamaya), physical (pranamaya), mental (manomaya), intellectual (vijnanamaya) and spiritual (anandamaya) levels within our being. Regular yoga practice creates mental clarity and calmness, increases body awareness, relieves chronic stress, relaxes the mind, centers attention, and sharpens concentration.

Empirical studies on yoga's effects on psychological well-being have been well documented (e.g., Gustavsson \& Harung, 1994) and have shown that practicing yoga can provide chronic pain sufferers with useful tools to actively cope with their pain and help counter feelings of helplessness and depression. Studies by Jella (1993) have also shown that increased brain activity due to pranayama is associated with better performance and can enhance cognitivefunctioning. Yogic stretching and breathing exercises have been shown to result in an invigorating effect on both mental and physical energy and improved mood (Singh, Shettiwar, \& Udupa, 1982). Yogic theory and practice lead to increased self-knowledge. This knowledge is not merely that of the practical kind relating to techniques, but of a spiritual sort harnessing the nature of the self at rest.

\section{The Problems of Employee Motivation}

Programs to motivate employees using reward and punishment schemes have been difficult to manage and have limited effectiveness. Despite good working conditions, high salaries and perks, employees are not happy or motivated. Harsh punishments also have failed to deter undesired behavior. Understanding individuals from the ashrama dharma (stages of life) perspective and providing them with appropriate policies that help in fulfilling purusharthas (goals of life) could help resolve motivational issues. One of the causes for the gap 
between organizational vision and individual vision is their conflicting goals. While organizations at a macro level practice vyapara dharma (objective business practices), individuals at the micro level would be motivated to practice vrutti dharma (objective professional/work responsibilities). When individuals and organizations both work beyond artha (material benefits/profits), and their driving force is the right path (dharma or actualization-moksha), external materialistic incentives lose prominence, enhancing the level of self-motivation. The philosophy of karma yoga (Bhagavadgita) orients individuals toward nishkama karma, that is, work devoid of selfish desire. Motivational strategies centering on purusharthas (goals of life) facilitate the employees toward achieving unison between personal self (atman) and universal self (Brahman). Thus various HR issues related to employee morale, motivation, ethics, and values and others are resolved as the formal, materialistic orientation of the workers is replaced by a more informal, subjective (non-egoistic), idealistic orientation by the regular practice of karma yoga.

Modern organizations are characterized by a flat structure, a high degree of flexibility, and incentives to climb the organizational hierarchy at a rapid pace (Leavitt, 2004). At the individual level this makes the employees self-centered. Employee attrition, lack of commitment and involvement, apathetic attitudes towards the organization and others at the workplace, are primarily due to selfcentered growth. Development of human resources cannot be blind to the individual's strategies toward personal growth and its corresponding consequences to the group and society. Thus, overall development of human resources should provide conditions for continuous growth in the organization for all.

People are social beings, and many of our social needs are gratified at work. With the advent of technological growth, many work environments provide a conducive physical environment yet may have a poor psychosocial environment. Developing training based on holistic Hindu perspective is needed. Many of the current stress management techniques (yoga, pranayama, meditation, and others) have a Hindu theoretical base. Many of these are being learned/trained at a surface level (as a set of bodily exercises) and thus have a temporary effect. Training modules with sound theoretical and practical groundwork based on ancient Hindu Upanishads, yoga sutras, and others will help the individual toward growth.

\section{Implications for Practice}

At the individual level, learning and following a way of life delineated in ashtanga yoga and karma yoga leads to self-realization. At the organizational level, changes in the organizational functioning could be brought about by providing an environment that fosters development of an internal frame of reference, a simple way of living, purity of heart and inner discovery/self-realization, and also comprehensive cosmic sense (Chakraborty, 2005). 


\section{Implications for Research}

The holistic model provided in Hinduism ensures the overall development of the individual, organization, and society. The principles advocated in the Upanishads and yoga sutras need to be understood properly before being implemented. Unfortunately, there are several contradictory commentaries on the meaning and application of sutras (principles). Training under a teacher (guru) is essential to ensure correct understanding and practice. While therapeutic applications of ashtanga yoga have been widely researched (Srivastava, 2001), the practice of ashtanga yoga (reorienting oneself toward purusharthas and training individuals in uncovering the sheaths or koshas) needs to be empirically studied. Establishing valid inferences regarding the benefits of these on the individual growth and development and the overall development of human resource in organizations is a challenging task.

\section{References}

Chakraborty, S. K. (2005). The management and ethics omnibus. New Delhi: Oxford University Press.

Gustavsson, B., \& Harung, H. S. (1994). Organizational learning based on transforming collective consciousness. The Learning Organization, 1 (1), 33-40.

Hellriegel, D., Slocum, J. W., Jr., \& Woodman, R. W. (1995). Organizational behavior (7th ed.). Minneapolis, MN: West.

Hiriyanna, M. (2002). Essentials of Indian philosophy, Varanasi, India: Banarasidas.

Jella, S.-K. (1993). The effects of unilateral forced nostril breathing on cognitive performance. International Journal of Neurosciences, 73 (1-2), 61-68.

Leavitt, H. (2004). Top down: Why hierarchies are here to stay and how to manage them more effectively. Cambridge, MA: Harvard Business School Press.

Radhakrishnan, S. (1953). The principal Upanishads. New York: Harper.

Singh, R. H., Shettiwar, R. M., \& Udupa, K. N. (1982). Physiological and therapeutic studies on yoga. The Yoga Review, 2 (4), 185-209.

Srivastava, S. P. (2001). Systematic survey of Indian psychology. Bahadurgaarh, India: Adhyathma Vijnana Prakashan.

H. S. Ashok is currently working in the Department of Psychology, Bangalore University, Bangalore, India. He has a postgraduate degree and a doctoral degree in psychology. He has teaching and research experience spanning over two decades. He is currently interested in research in the area of competency framework and psychometric testing for organizational use.

M. S. Thimmappa recently left his office as vice chancellor of Bangalore University, Bangalore, India. He has served the Bangalore University under various capacities: as professor and head of the Department of Psychology, registrar, and vice chancellor. He is a trained clinical psychologist and a popular trainer in the area of human relations in the workplace.

Ashok, H. S., \& Thimmappa, M. S. (2006). A Hindu worldview of adult learning in the workplace. Advances in Developing Human Resources, 8(3), 329-336. 